\title{
Completion phenomenon in transcortical sensory aphasia
}

\author{
Y. Nakagawa1 ${ }^{1}$, H. Tanabe ${ }^{1,2}$, M. Ikeda ${ }^{2}$, H. Kazui ${ }^{1}$, K. Ito ${ }^{3}$, N. Inoue ${ }^{4}$, \\ Y. Hatakenaka ${ }^{5}$, T. Sawada ${ }^{4}$, H. Ikeda ${ }^{5}$ and J. Shiraishi ${ }^{1}$ \\ ${ }^{1}$ Faculty of Health and Sport Sciences, Osaka University, ${ }^{2}$ Department of Neuropsychiatry, \\ Osaka University Medical School, '3epartment of Neuro-psychiatry, Ozone Hospital, \\ ${ }^{4}$ Cerebrovascular Division, Department of Medicine, National Cardiovascular Center, \\ ${ }^{5}$ Department of Neuropsychiatry, Kochi Medical School, Japan
}

Correspondence to: Y. Nakagawa, Hyogo Institute for Aging Brain and Cognitive

Disorders, Saisho-ko 520, Himeji, 670, Japan

\begin{abstract}
We investigated completion phenomenon for proverbs in cases demonstrating transcortical sensory aphasia due to a variety of diseases. Lack of this completion was exclusively observed in patients with focal atrophy. These patients showed a selective and consistent impairment in word comprehension without phonemic cue effects in naming. The completion phenomenon was present in patients demonstrating transcortical sensory aphasia due to other cerebral diseases. In these patients, comprehension deficits were not selective for words, or words not comprehended were inconsistent and some phonemic cue effects were observed. In a previous study, we reported that completion phenomena for multiplication tables, serial numbers and names of days were frequently noted in patients with focal atrophy. Together with the present findings, these results suggest that lack of proverb completion may be attributed to a selective, systematic and complete loss of the meaning representations for language units such as words and proverbs. In addition, pathological processes of focal atrophy with temporal predominance might selectively affect the semantic memory for language as a unit.
\end{abstract}

Keywords: Completion phenomenon - Focal atrophy - Gogi aphasia - Semantic memory - Transcortical sensory aphasia

\section{INTRODUCTION}

In 1943, Imura described an aphasic syndrome, and named it Gogi (word meaning) aphasia (Imura, 1943). Impairments in this aphasia can be attributed to a selective dysfunction in use of semantic aspects of words, with relatively well-preserved phonological processing. Patients with this aphasia apparently receive and perceive auditory signals adequately, as demonstrated by accurate verbal repetition. However, they have marked difficulty in extracting the meaning of words, in addition to conspicuous and severe word finding difficulty (Sasanuma and Monoi, 1975; Tanabe et al., 1992). The selective dysfunction of semantic processing is reflected in impairment of the ability to process Kanji (ideogram) as opposed to a marked preservation of the ability to process Kana (phonogram). In this respect, Gogi aphasia is peculiar to Japanese. As ability to repeat words or sentences is well preserved, Gogi aphasia is thought to be a kind of transcortical sensory aphasia (TCSA).

In patients with TCSA, series speech is usually preserved and completion phenomena are frequently observed (Benson, 1979). If a nursery rhyme, poem or overlearned statement is begun by the examiner, it can be completed easily and almost automatically by the patient without understanding of its meaning. In our previous study (Tanabe et al., 1992), however, we noticed that completion phenomenon of proverbs was rarely observed in the Gogi aphasics with focal atrophy. Therefore, the purpose of this investigation was two-fold: (1) Is the absence of proverb completion exclusive to patients with TCSA or Gogi aphasia due to focal atrophy? In other words, is the pathological mechanism underlying TCSA due to focal atrophy different from that underlying TCSA due to other cerebral diseases? (2) If so, what is the mechanism? We studied 22 patients who developed TCSA following various diseases.

\section{METHODS}

\section{Subjects}

Twenty-two patients with TCSA were included in this study. We adopted Kertesz's criteria for TCSA, that is, fluent speech with good repetition but poor comprehen- 
TABLE I. Demographic details of 22 patients with TCSA

\begin{tabular}{|c|c|c|c|c|}
\hline Patient group & $\begin{array}{l}\text { Patient } \\
\text { No. }\end{array}$ & Age & Sex & $\begin{array}{l}\text { Duration } \\
\text { of illness }\end{array}$ \\
\hline A (focal atrophy) & $\begin{array}{l}\text { A1 } \\
\text { A2 } \\
\text { A3 } \\
\text { A4 } \\
\text { A5 } \\
\text { A6 } \\
\text { A7 } \\
\text { A8 }\end{array}$ & $\begin{array}{l}71 \\
59 \\
64 \\
73 \\
58 \\
69 \\
71 \\
60\end{array}$ & $\begin{array}{l}M \\
M \\
F \\
F \\
M \\
M \\
M \\
F\end{array}$ & $\begin{array}{l}3 \text { years } \\
3 \text { years } \\
3 \text { years } \\
1 \text { year } \\
8 \text { years } \\
5 \text { years } \\
3 \text { years } \\
5 \text { years }\end{array}$ \\
\hline B (diffuse atrophy) & $\begin{array}{l}\text { B1 } \\
\text { B2 } \\
\text { B3 } \\
\text { B4 } \\
\text { B5 }\end{array}$ & $\begin{array}{l}78 \\
65 \\
81 \\
70 \\
64\end{array}$ & $\begin{array}{l}F \\
F \\
M \\
F \\
F\end{array}$ & $\begin{array}{l}5 \text { years } \\
4 \text { years } \\
5 \text { years } \\
6 \text { years } \\
5 \text { years }\end{array}$ \\
\hline C (MNDD) & $\mathrm{C}$ & 64 & $M$ & 2 years \\
\hline $\mathrm{D}(\mathrm{CVD})$ & $\begin{array}{l}\text { D1 } \\
\text { D2 } \\
\text { D3 } \\
\text { D4 } \\
\text { D5 }\end{array}$ & $\begin{array}{l}76 \\
77 \\
72 \\
51 \\
64\end{array}$ & $\begin{array}{l}M \\
M \\
M \\
F \\
M\end{array}$ & $\begin{array}{c}3 \text { months } \\
2 \text { months } \\
1 \text { month } \\
7 \text { months } \\
8 \text { months }\end{array}$ \\
\hline E (brain tumor) & $\begin{array}{l}\text { E1 } \\
\text { E2 }\end{array}$ & $\begin{array}{l}79 \\
57\end{array}$ & $\begin{array}{l}M \\
M\end{array}$ & - \\
\hline F (herpes encephalitis) & $\mathrm{F}$ & 46 & $M$ & 1 year \\
\hline
\end{tabular}

sion and naming (Kertesz, 1979). Aphasic types were generally classified using the standard language test of aphasia (SLTA) (Takeda, 1977), Marie's 3 paper test, and a test for Gogi aphasia devised by Tanabe et al. (1992). During spontaneous speech, all patients spoke fluently with normal syntax, but with limited vocabulary, and echoic responses were present to some extent. Verbal paraphasic errors were sometimes observed, while literal paraphasias were very rare. Although they could all repeat simple sentences which were composed of two or three words, they could not comprehend words commonly used in daily life. In addition they demonstrated severe word finding difficulty.

The patients with TCSA were divided into six groups according to the clinical and neuroimaging findings (Table I). Group A consisted of eight patients with focal brain atrophy. Patient A1 showed recognition deficits of familiar faces as well as TCSA. Since their comprehension deficits were restricted to words, they were all specifically diagnosed as having Gogi aphasia (Tanabe et al., 1992). Words they could not comprehend were consistent from one occasion to another; the wife of patient A5 complained that each morning he could not comprehend the common word "towel". In reading Kanji compounds, they had a tendency to phonetically pronounce each individual Kanji without understanding the meaning as a whole. Computed tomography (CT) or magnetic resonance imaging (MRI) scans of all the patients disclosed knife-edged atrophy of the bilateral anterior temporal lobes, more prominent on the left in seven patients and on the right in one (Patient A1) (Fig. 1). Single photon emission computed tomography (SPECT) scans, performed on all members of this group except for Patients A6 and A7, revealed hypoperfusion corresponding to the atrophic areas shown by MRI (Fig. 2). Patient A8, whose MRI disclosed atrophy of the left parietal lobe in addition to the left anterior temporal lobe atrophy, showed mild difficulties in Kana writing. They were all diagnosed as having Pick's disease since they had circumscribed cerebral cortical atrophy (Onari and Spatz, 1926). Group B consisted of five patients with diffuse cerebral cortical atrophy. They all exhibited amnesia and posterior cortical symptoms such as visuospatial disturbances and dyspraxia in addition to TCSA. CT scans of these patients revealed diffuse cortical atrophy. SPECT scans performed on Patients B1 and B5 revealed hypoperfusion in the bilateral temporoparietal areas. Clinical diagnosis of these patients was dementia of the Alzheimer type. Group C was composed of a single case of motor neuron disease with dementia (MNDD) (Mitsuyama, 1984), later verified by autopsy. In daily conversation, his verbal output consisted of very short phrases, echolalia and completion phenomena for his personal history, such as his own name, his date of birth and his address. MRI revealed slight cortical atrophy in the bilateral frontal and anterior temporal lobes, but striking hypoperfusion was disclosed in these regions by SPECT scans. The 14 patients in Groups A, B and C had a history of insidiously progressive decline in language skills of more than one year duration. Group D was a group of five patients with cerebrovascular disease (CVD). Like patient $\mathrm{C}$, echolalia was prominent in all of them during daily conversation. CT scans revealed low density areas in regions involving posterior portions of the left hemisphere in Patients D3 , D4 and D5, and in the left frontal lobe in Patients D1 and D2, not involving the Broca-Wernicke area complex. Group $\mathrm{E}$ was composed of two patients with brain tumor. Patients E1 and E2 had metastatic adenocarcinoma and meningioma, respectively. Patient E2 showed mild articulatory disturbance in addition to TCSA. CT scans showed left parieto-occipital metastatic adenocarcinoma in Patient E1 and meningioma compressing the parasagittal surface of the left frontotemporal region in Patient E2. Finally, Group F consisted of a single patient with Gogi aphasia caused by herpes simplex encephalitis. Like patients of Group A, he had a deficit of individual word comprehension together with selective impairment in Kanji processing. Unlike patients in Group A, however, the words not comprehended varied from one occasion to another; in natural settings, he sometimes used names of 

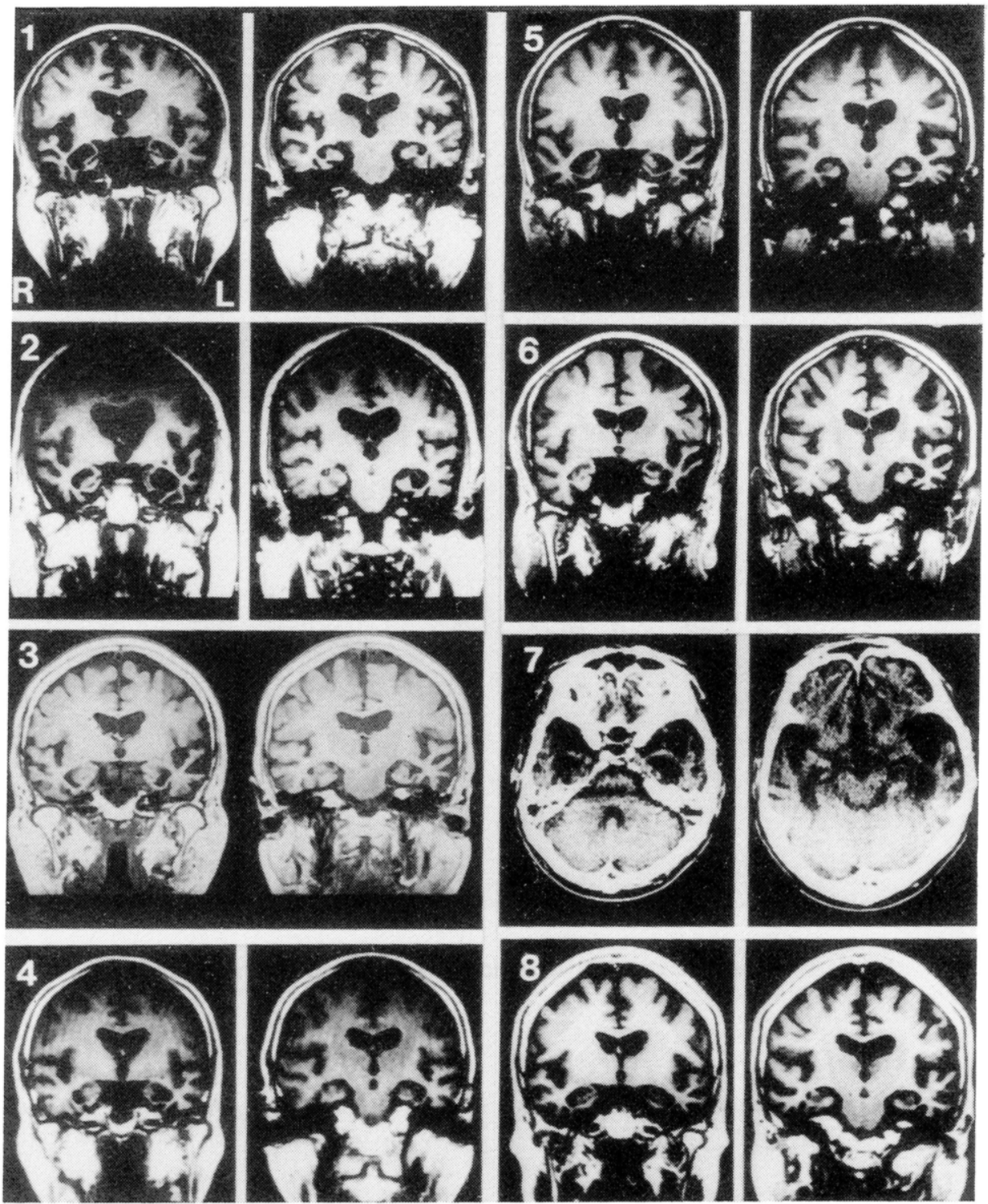

FIG. 1. Coronal magnetic resonance imagings of seven patients in Group A, and a transverse computed tomography scan of Patient A7.

objects which he could not name on command. MRI (Fig. 3) and SPECT scans (Fig. 4) of Patient F disclosed damage to the left anterior temporal lobe and medial aspect of the right temporal lobe.

\section{Procedure}

Patients were evaluated with a completion task for proverbs (proverb completion task), and a picture naming task to investigate their word completion ability.

In the proverb completion task, 10 well-known Japanese proverbs were presented as stimuli. When an examiner states the beginning of a proverb, the patient may not only repeat what has been said but may also con- tinue the proverb to completion, or only continue without repetition. For example, one Japanese proverb is "Saru mo ki kara ochiru [Even a monkey falls from a tree]", which resembles "Even Homer sometimes nods" in its meaning. When an examiner states "Saru mo... [Even a monkey... ]", the patient may answer "(Saru mo) ki kara ochiru" without understanding the meaning of his reply. If unable to answer, the patient was given some additional phonemes, "Saru mo ki kara...", and was asked to attempt the completion again. This procedure was continued, with increasing additional phonemes being given, until the proverb was correctly stated. When the patient could complete the target proverb at any stage of cueing, 


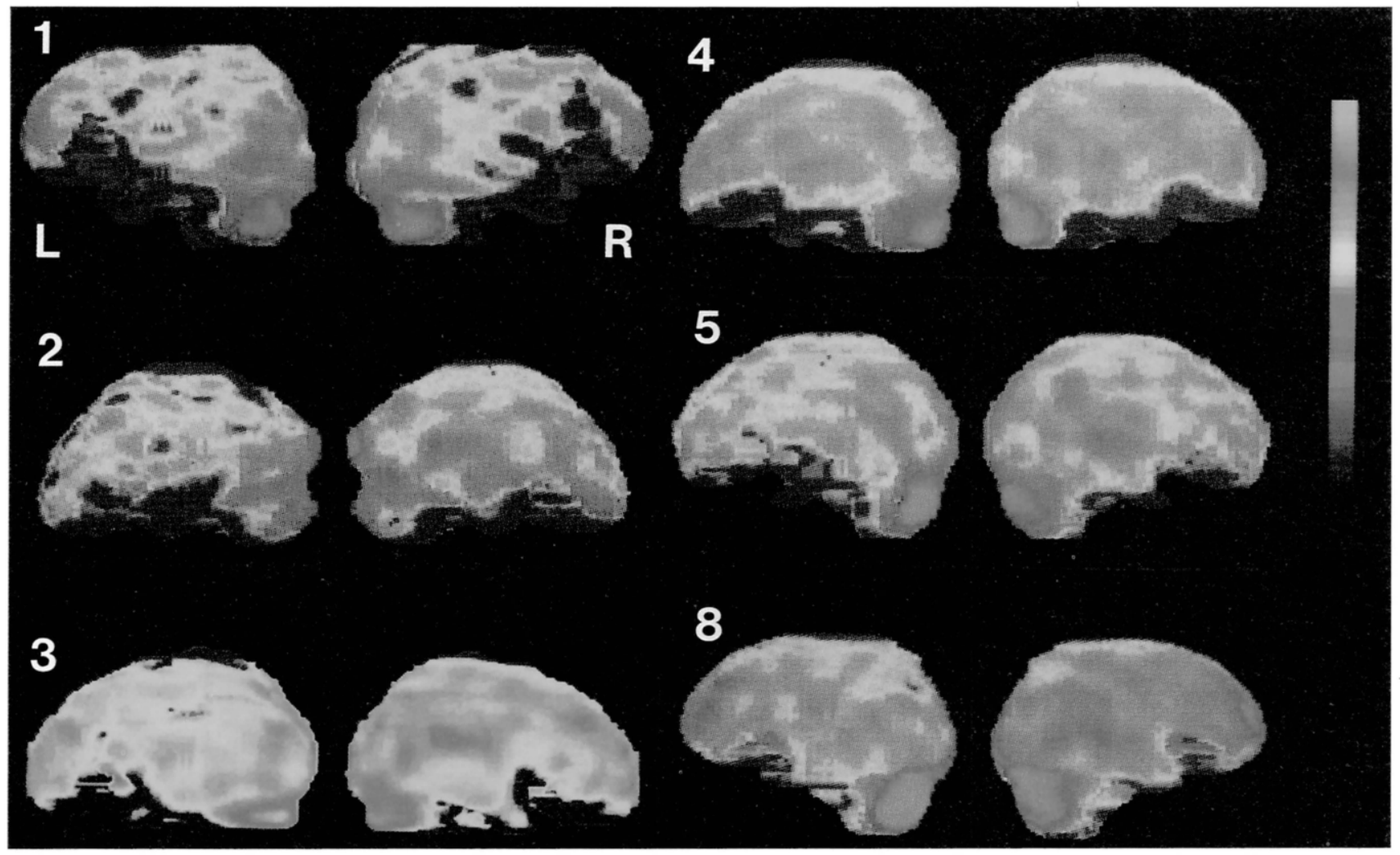

FIG. 2. Three-dimensional surface single photon emission computer tomography scans of patients $A 1, A 2, A 3, A 4, A 5$ and $A 8$.
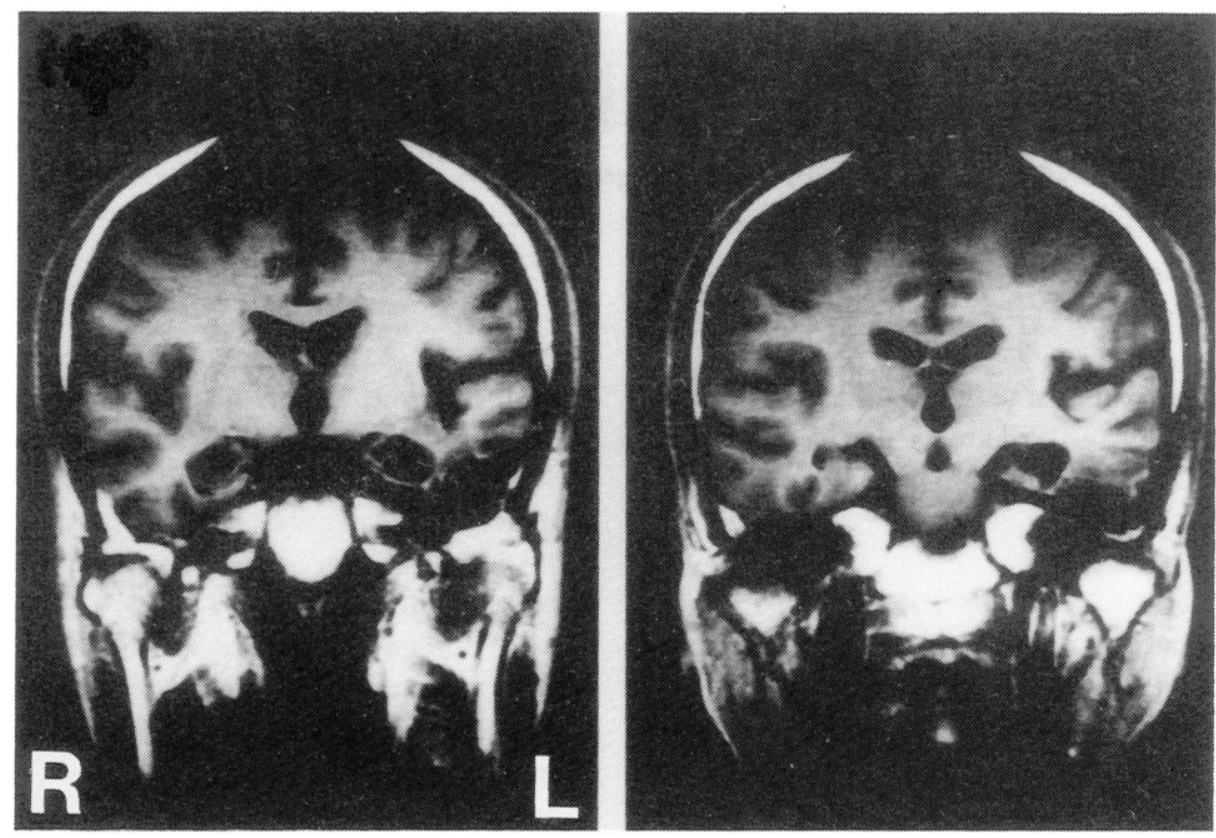

FIG. 3. Coronal magnetic resonance imagings of Patient F. 


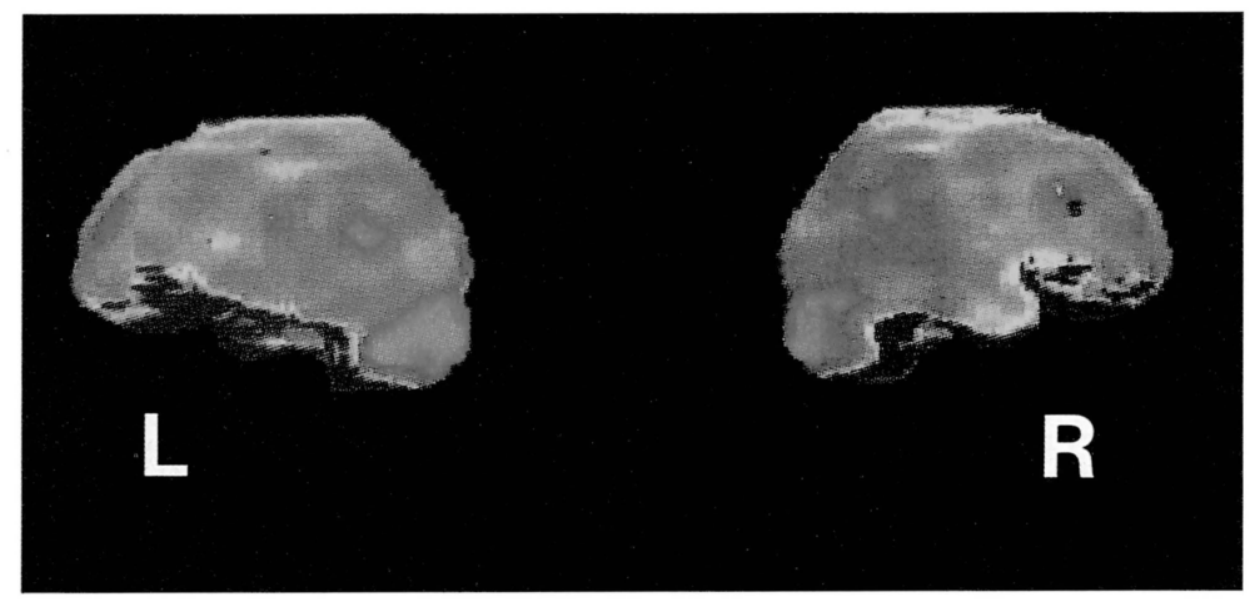

FIG. 4. Three-dimensional surface single photon emission computed tomography scans of patient F.

the completion phenomenon of the proverb was judged to be present. When the patient could not succeed in completion even if given additional phonemes, or made incorrect answers such as literal paraphasias, we regarded these responses as errors. The quality and quantity of errors were analyzed. At the time of testing, the examiner also checked whether or not the patients comprehended the meaning of the proverb, by asking them to explain it orally, or by asking them to choose a proverb semantically similar to the target proverb with a multiple task.

The abilities of picture naming and also of word completion were evaluated by performances on the SLTA for 15 patients and by a similar test for the other seven patients (Patients A3, B1, B2, B4, B5, E1 and E2). If a patient could not name a picture in $15 \mathrm{~s}$, an initial phoneme of the target word was given.

\section{RESULTS}

\section{Group A (TCSA, or specifically Gogi aphasia/focal atrophy)}

For the proverb completion task, comprehension of proverbs was severely impaired in all the patients of this group. However, they sometimes showed preserved comprehension of individual words contained in the proverbs. Regardless of their comprehension of these individual words, the completion phenomenon was totally absent in all the patients except for Patient A4, who showed relatively mild Gogi aphasia (Table II). Their errors in this task mostly consisted of "I don't know" responses. When Patient A4, who could complete a few proverbs, heard the beginning of one proverb, "Saru mo... [Even a monkey ... ]", she replied, "ki kara oriru [comes down from a tree]" instead of "ki kara ochiru [falls from a tree]". She completed another proverb with a phonemic error. Therefore, the errors of Patients A4 were composed of a substi-
TABLE II. Results of completion task and naming task

\begin{tabular}{|c|c|c|c|}
\hline & \multirow{2}{*}{$\begin{array}{l}\text { Completion } \\
\text { task score }\end{array}$} & \multicolumn{2}{|c|}{ Picture naming task } \\
\hline & & Score & Cueing score \\
\hline A1 & $0 / 10$ & $12 / 20$ & $14 / 20$ \\
\hline A2 & $0 / 10$ & $11 / 20$ & $11 / 20$ \\
\hline A3 & $0 / 10$ & $4 / 15^{\star \star}$ & n.a. \\
\hline A4 & $2 / 4^{\star}$ & $7 / 20$ & $7 / 20$ \\
\hline A5 & $0 / 10$ & $7 / 20$ & $7 / 20$ \\
\hline A6 & $0 / 10$ & $5 / 20$ & $6 / 20$ \\
\hline A7 & $0 / 5^{\star}$ & $4 / 20$ & $4 / 20$ \\
\hline A8 & $0 / 3^{*}$ & $1 / 20$ & $1 / 20$ \\
\hline B1 & $3 / 10$ & $5 / 10^{\star \star}$ & n.a. \\
\hline B2 & $9 / 10$ & $2 / 4^{\star \star}$ & $3 / 4$ \\
\hline B3 & $8 / 10$ & $8 / 20$ & $9 / 20$ \\
\hline B4 & $4 / 10$ & $3 / 9^{\star \star}$ & $4 / 9$ \\
\hline B5 & $1 / 5^{\star}$ & $0 / 3^{\star \star}$ & $1 / 3$ \\
\hline C & $4 / 10$ & $7 / 20$ & $14 / 20$ \\
\hline D1 & $2 / 3^{\star}$ & $9 / 20$ & $10 / 20$ \\
\hline D2 & $8 / 10$ & $6 / 20$ & $7 / 20$ \\
\hline D3 & $1 / 2^{\star}$ & $1 / 20$ & $3 / 20$ \\
\hline D4 & $5 / 10$ & $0 / 20$ & $4 / 20$ \\
\hline D5 & $7 / 10$ & $0 / 20$ & $0 / 20$ \\
\hline E1 & $3 / 3^{\star}$ & $5 / 7^{\star \star}$ & $6 / 7$ \\
\hline E2 & $2 / 3^{\star}$ & $2 / 4^{\star \star}$ & $3 / 4$ \\
\hline $\mathrm{F}$ & $6 / 10$ & $8 / 20$ & 9/20 \\
\hline
\end{tabular}

Each score = number correct/number administered.

*Partly assessed; **assessed by tests similar to naming task of SLTA; n.a., not assessed.

tution of another word semantically similar to the word contained in the target proverb and a literal paraphasia.

In picture naming, errors mainly consisted of "I don't know (what it was called)" responses and partly of verbal paraphasic responses. There were few literal paraphasias. Patient A5 failed to name the picture and often replied "I 
don't know", although he could explain what an object was or how to use it. Phonemic cues were generally ineffective for patients of Group A, although Patients A1 and A6 benefited from cueing for two words and one word, respectively (Table II). When Patient A7 heard a phonemic cue "Goha ..." of the target word "Gohan" (rice), he replied, "Goha? What is goha?" Even when the whole word "gohan" was given, he could not comprehend the meaning of the word and moreover, no signs of familiarity with it were noted.

\section{Group B (TCSA/diffuse atrophy)}

In the proverb completion task, comprehension of proverbs was severely impaired in all patients of this group. Although they showed various errors, completion phenomena themselves were frequently observed (Table II). Even when they failed to complete it, rhyme or rhythm of the target proverb was frequently preserved in their responses; when Patient B2 heard the first several syllables "Köbo mo fude no" of the target proverb "Köbo mo fude no ayamari [Even Köbo (a great calligrapher) sometimes makes mistakes in calligraphy]", he only replied, "ara" (a phonemic error) instead of saying "ayamari", and stopped his answer. When the examiner stated again the beginning of the proverb with additional syllables "Kobo mo fude no aya", he could complete the proverb correctly. In addition to these phonemic errors, patients also occasionally used words semantically related to the correct words contained in the proverbs, i.e. they made semantic errors. Patient B1, for example, used the word "aru" which means "presence" and is the opposite of the correct word "nashi" which means "absence". One of these semantic errors had the same rhyme as the word in the target proverb, whilst the others did not.

Patients in this group demonstrated difficulties in naming. Their performance on this task was characterized by word finding difficulty, with some phonemic cue effects (Table II).

\section{Group C (TCSA/MNDD)}

In the proverb completion task, comprehension of proverbs was impaired but the completion phenomenon was relatively well preserved in Patient C (Table II). Performance of the naming task was disturbed and resembled that of patients in Group B, except that phonemic cues in naming were more effective for Patient $\mathrm{C}$ than for Group B patients (Table II).

\section{Group D (TCSA/CVD)}

In the proverb completion task, patients of Group D could not understand the meaning of proverbs but could complete them to some extent (Table II). Like the patients in Group B, they sometimes produced literal paraphasias and substituted another word semantically related to the correct word, e.g. "butsukaru [touch]" instead of the correct word "ataru [hit]", or the word "ketsu" (a slang word for hip) instead of the correct word "shiri [hip]".

These patients showed severe anomia, but in the naming task phonemic cues were sometimes effective (except for Patient D5: Table II), as was found for patients of Groups $\mathrm{B}$ and $\mathrm{C}$.

\section{Group E (TCSA/brain tumor)}

For Group E patients, completion phenomena for proverbs were almost present despite their difficulty in comprehending proverbs (Table II). In the naming task, the nature of their errors was essentially the same as that of Groups B, $\mathrm{C}$ and D. Phonemic cues sometimes aided them in naming (Table II).

\section{Group F (TCSA, or specifically Gogi aphasia/ herpes simplex encephalitis)}

In the completion task, the patient benefited from cueing to some extent, although he exhibited marked impairment in comprehending proverbs (Table II). He often showed some degree of familiarity with the proverbs even when he could not understand them and occasionally responded to the task with paraphasias. When the examiner stated the beginning "Wataru seken ni ... [Wherever you live, you can ... l" of the target proverb "Wataru seken ni oni wa nashi [Wherever you live, you can meet kind people]" ("oni" means a cold-hearted man), he replied, "oyu ga nai" ("oyu" means hot water).

Unlike the patients of Group A but akin to those of Groups B, C, D and E, word finding difficulty was accompanied by some phonemic cue effects.

\section{DISCUSSION}

Completion phenomena in TCSA patients are generally thought to represent preserved automatic aspects of speech (Benson, 1979). The patients in Groups B, C, D, E and $\mathrm{F}$, in execution of the proverb completion task, benefited from cueing and could complete some proverbs, without understanding their meaning. Even when they could not complete them, thyme or rhythm of the target proverb was often observed in their responses. Thus, they appeared to retrieve the proverb via phonological tactics. For the rest of the proverb, they made some literal paraphasic errors which would not be noticeable in natural settings, possibly because phonological tactics were used in the task. They occasionally produced verbal paraphasic errors, which were generally semantically related to the target proverb. Two of these verbal paraphasias rhymed with the word in the target proverb, e.g. the word "oyu [hot water]" was substituted for "oni [a cold-hearted man]". 
The other errors were not phonologically related but semantically related to the target proverb despite patients' incomprehension of the proverbs' meaning, as illustrated by the substitution of the slang word "ketsu [hip]" for "shiri [hip]". These errors suggest that phonological and semantic stores of proverbs are at least partially preserved in these patients.

In contrast, completion phenomenon of proverbs was totally absent in all patients in Group A except for Patient A4, whether or not they could comprehend each word contained in the proverb. They lacked any sign of familiarity with almost all of the proverbs. Patient A4, who could complete two of four proverbs, showed relatively mild Gogi aphasia with the shortest duration of illness in the group (Table II), as well as an anomic pattern in daily conversation (severe deficits in naming but moderate disturbance in comprehension). Since her language ability was not completely impaired, she could complete a few proverbs. Cummings et al. reported that TCSA patients with Alzheimer's disease lacked completion phenomenon for nursery rhymes (Cummings et al., 1985). In our study, however, patients in Group B, who were clinically diagnosed as having Alzheimer's disease, responded to cues with a similar frequency to patients with CVD. "Lack of completion phenomenon" as described by Cummings et al. implied relative decline of this phenomenon and appears to be qualitatively different from the impairment seen in patients of Group A. The absolute decline or absence of proverb completion was specific to TCSA in patients with focal atrophy in the present study. The question arises as to why Group A patients could not retrieve phonological or semantic fragments of proverbs even with use of the completion assistance technique, whilst the other TCSA patients could. The absence of completion cannot be attributed to incomprehension of the meaning of individual words contained in the proverbs, because they failed to complete the proverb even when they did demonstrate an understanding of the words. Furthermore, our previous study suggested that this absence cannot be attributed to impairments in automatic aspects of speech. The study investigated completion responses for other overlearned phrases or series speech in patients with transcortical sensory aphasia due to focal atrophy. Completion responses for multiplication tables, serial numbers, and names of days were frequently noted (Nakagawa et al., 1993). In consideration of this material selectivity in completion, lack of response for proverbs cannot be explained by deficits in automatic aspects of speech. Proverbs, multiplication tables, serial numbers, and names of days have common features in terms of phonologically overlearned phrases, but proverbs, unlike other overlearned phrases and more akin to words, have symbolic meanings as a whole. The latter aspect of proverbs may be reflected in the lack of proverb completion. To clarify this issue, the performance of word completion in patients was compared.

TCSA shown by patients of Groups B, C, D and E was characterized by severe anomia with some phonemic cue effects. These effects indicate that the lexical stores themselves are not wholly destroyed. Only Patient D5, who showed the severest TCSA in Group D, did no benefit from cues of an initial phoneme of the target word in SLTA. If patients in these groups including Patient D5 were given additional phonemes in the picture naming task, these phonemes might prove beneficial as occurred during the proverb completion task. As to the lesion location, although Groups B, C, D and E patients showed a distribution of lesions in the left hemisphere, their lesions existed outside the Broca-Wernicke area complex. Thus, partial isolation of the speech area from the association cortex may account for the comprehension difficulty of these patients, resulting in an apparent two-way disturbance in word comprehension; i.e. they can neither name an object nor identify an object when the name is given.

Patients of Groups A and F, who were Gogi aphasics, can be distinguished from other patients in that their comprehension deficits are restricted to words, especially to nominal terms (Tanabe et al., 1992). Patient F showed anomia with some phonemic cue effects. The words he could not comprehend were not consistent from one occasion to another. Hence, the confinement of his inability to word understanding could be attributed to a failure to associate semantic and lexical knowledge, or to partial destruction of semantic memory for words. Caselli et al. (1991) reported a similar case to Patient F, in which the left anterior temporal lobe was also involved, and coined the phrase "associative anomia". In contrast to these cases, patients in Group A showed profound and consistent difficulties in word comprehension. Phonemic cues were generally ineffective for Group A patients. The words not comprehended were consistent from one occasion to another. In addition, these patients often lacked any sign of familiarity with words, as observed in the proverb completion task. These findings suggest that the impairment in word understanding could be attributed to a loss of lexicon or degradation within the meaning representations themselves, rather than a failure of access to them. In the literature, such a selective and severe disturbance of word comprehension has so far been exclusively observed in cases of focal atrophy with temporal predominance (McCarthy and Warrington, 1988; Tyrrel et al., 1990; Snowden et al., 1992; Hodges et al., 1992).

Even if patients of Groups $\mathrm{A}$ and $\mathrm{F}$ had a common lesion in the left anterior temporal lobe, degradation within the meaning representations of words and proverbs was not recognized in Patient $F$ who suffered from herpes simplex encephalitis. These findings might indicate that the degeneration process of focal atrophy with temporal pre- 
dominance selectively involves the semantic memory system as a unit.

\section{Acknowledgements}

The authors thank Mrs A. Kashiwagi, Mrs N. Ihori (Kyoritsu Rehabilitation Hospital), Dr Y. Ikemura, Dr Y. Yanagi (Mihara Hospital), Miss M. Kozawa (Yukioka Hospital), Dr T. Mori and $\mathrm{Mr}$ K. Komori (Higashi Kakogawa Hospital) for their help in testing the patients.

\section{REFERENCES}

Benson DF (1979) Aphasia, Alexia, and Agraphia. Churchill Livingston, New York.

Casselli R (1991) Associative anomia: dissociating words and their definitions. Mayo Clinic Proceedings, 66, 783-791.

Cummings JL, Benson DF, Hill MA and Read S (1985) Aphasia in dementia of the Alzheimer type. Neurology, 35, 394-397.

Hodges JR, Patterson K, Oxbury S and Funnell E (1992) Semantic dementia; progressive fluent aphasia with temporal lobe atrophy. Brain, 115, 1783-1806.

Imura T (1943) Aphasia: characteristic symptoms in Japanese. Psychiatra et Neurologia Japonica, 46, 196-218.

Kertesz A (1979) Aphasia and Associated Disorders. Grune \& Stratton, New York.

McCarthy RA and Warrington EK (1988) Evidence for modality-specific meaning systems in the brain. Nature, 334, 428-430.
Mitsuyama Y (1984) Presenile dementia with motor neuron disease in Japan: clinico-pathological review of 26 cases. Journal of Neurology Neurosurgery and Psychiatry, 47, 953-959.

Nakagawa Y, Tanabe H, Ikeda M, et al. (1993) Gogi aphasia due to lobar atrophy-Completion phenomenon for proverbs. Higher Brain Function Research, submitted.

Onari K and Spatz H (1926) Anatomische Beiträge Zur Lehre von der Pickschen umschriebenen Grosshirnrinden-Atrophie "Picksche Krankheit". Zeitschrift fur die gesamte Neurologie und Psychiatrie, 101, 470-511.

Sasanuma S and Monoi H (1975) The syndrome of Gogi (word meaning) aphasia. Selective impairment of Kanji processing. Neurology, 25, 627-632.

Snowden JS, Neary D, Mann MA, Goulding PJ and Testa HJ (1992) Progressive language disorder due to lobar atrophy. Annals of Neurology, 31, 174-183.

Takeda K (1977) Standard language test of aphasia: detailed description of construction of aphasia test in Japanese. Advanced in Neurological Sciences, 21, 1002-1013.

Tanabe H, Ikeda M, Nakagawa Y, et al. (1992) Gogi (word meaning) aphasia and semantic memory for words. Higher Brain Function Research, 12, 153-167.

Tyrrel PJ, Warrington EK, Frackowiak RSJ and Rossor MN (1990) Heterogeneity in progressive aphasia due to focal cortical atrophy. A clinical and PET study. Brain, 113, 1321-1336.

(Received 18 June 1993; accepted 10 July 1993) 


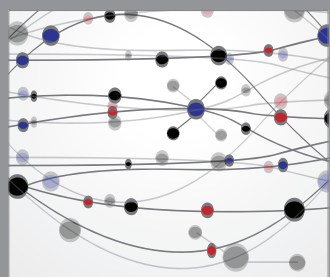

The Scientific World Journal
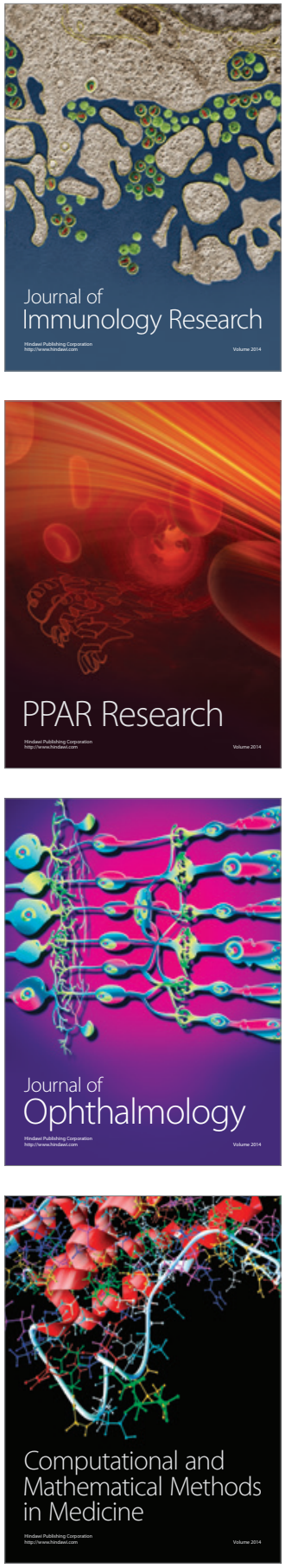

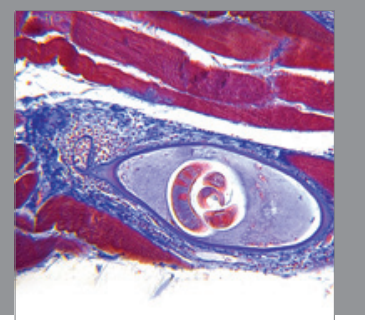

Gastroenterology

Research and Practice
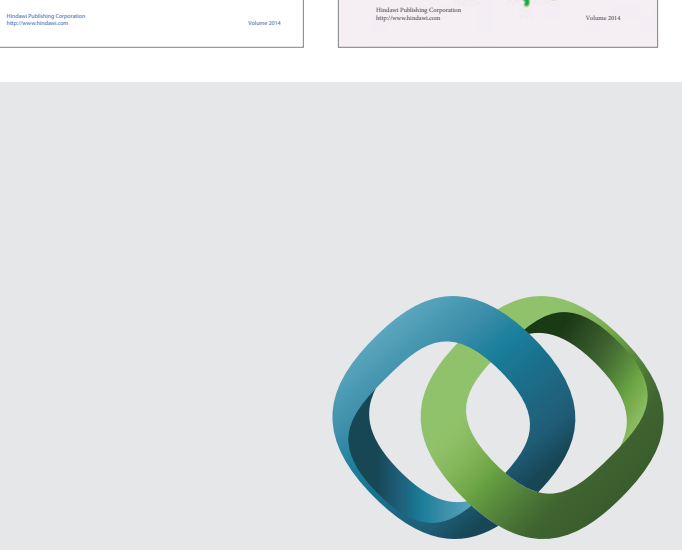

\section{Hindawi}

Submit your manuscripts at

http://www.hindawi.com
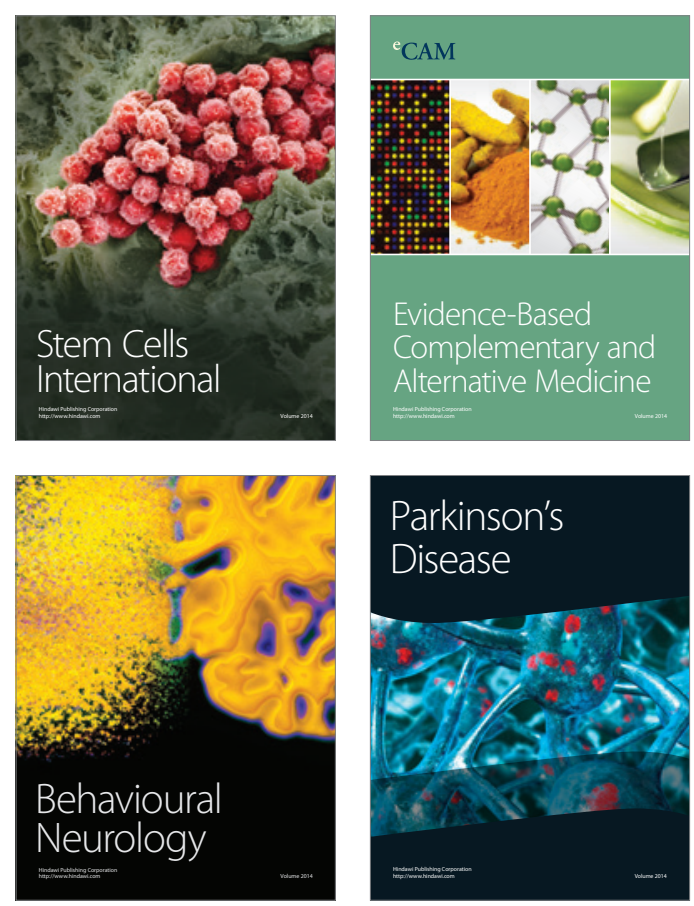

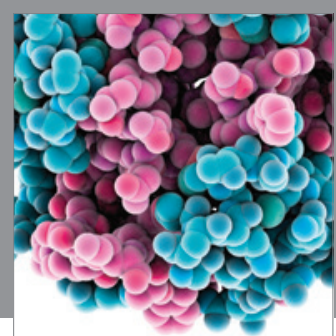

Journal of
Diabetes Research

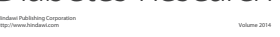

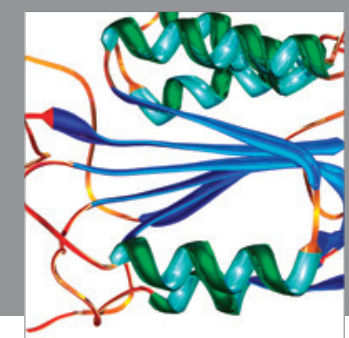

Disease Markers
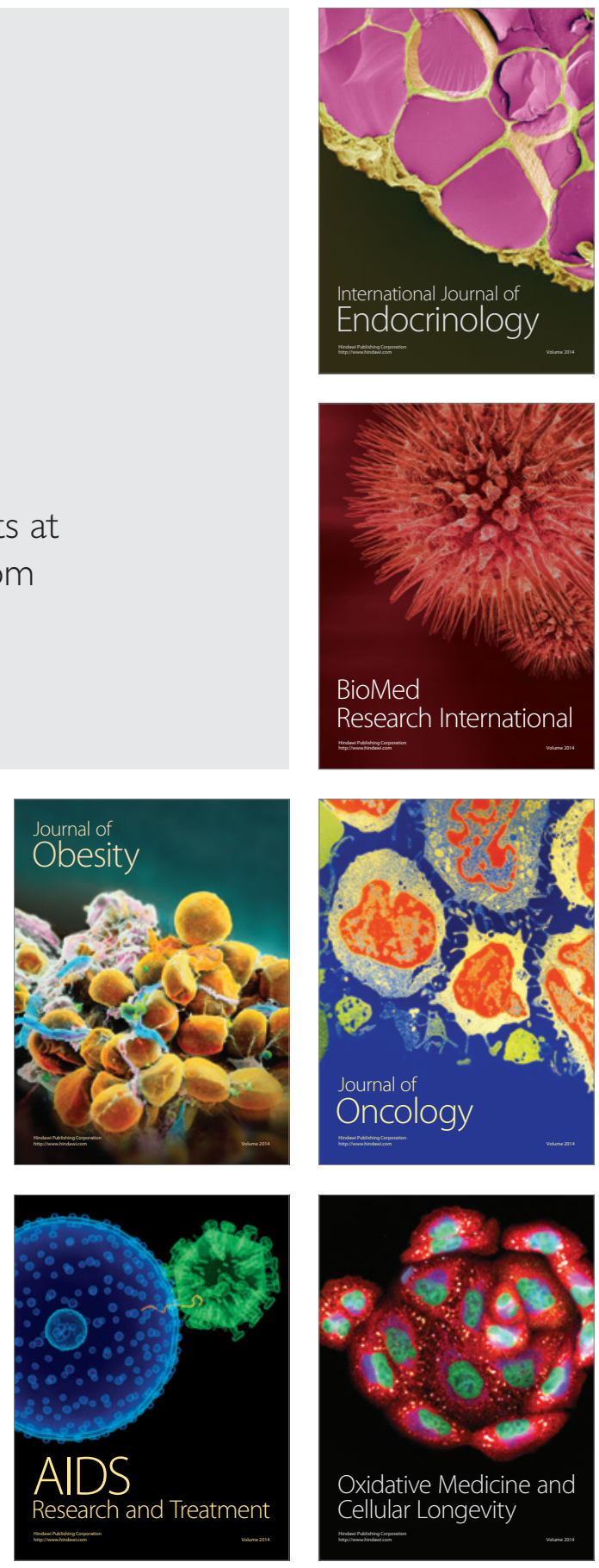